Waste and Resource Management Volume 170 Issue WR1

Analysis of the structure and values of the European Commission's Circular

Economy Package

Stahel

ice | proceedings

\title{
Analysis of the structure and values of the European Commission's Circular Economy Package
}

\author{
Walter R. Stahel MA Arch, Dr h.c. mult. \\ Founder-Director, Product-Life Institute Geneva, Geneva, Switzerland \\ (wrstahel2014@gmail.com)
}

\begin{abstract}
The present Circular Economy Package (EC CE Package) as proposed by the European Commission in December 2015, symbolised by its diagram below, turns the linear industrial economy into a circle and adds a phase 'from waste to resources' after waste management. It is built on a 'historic view' of protecting the environment and efficient waste management, of continuous flow processes and of seeing the future mostly as building on the past. The EC CE Package considers both natural capital (water, bioeconomy) and manufactured capital.
\end{abstract}

This critical analysis uses the 'the future is now' approach, based on value preservation and stock management (waste prevention): it uses foresight and backcasting to break out of the present EC CE view; it considers only manufactured capital. The EU Waste Directive then ought to be renamed EU Waste Prevention Directive; the 'consumption' phase becomes 'use/utilisation' its key actors are owner-users and pro-users (Toffler's prosumer) (Figure 1).

This briefing paper shares the EC CE Package's objective to maintain the value of the products, materials and resources for as long as possible, while minimising the generation of waste, and agree on the priorities of the 2008 EU waste directive of reuse, service-life extension and preparation for reuse (of goods) - what he calls the era of ' $R$ '. The two approaches agree that production (value-added flow managements, a 'river' economy) and circular economy (value-preserving stock management, a 'lake' economy) will operate in parallel: production is necessary to develop and bring to market novel solutions (the Internet of Things, smart packaging) and quantum leap innovation.

The two approaches differ as this critical analysis includes the impact of future opportunities (e.g. selling goods as services, recycling atoms) and considers the impacts of the circular economy (e.g. much less need for transport and packaging due to its local/regional nature), as well as new techno-commercial loop opportunities within the circular economy (the era of local ' $R$ ': reuse, repair, remanufacturing). The Roadmap to a Resource Efficient Europe (EC, 2011) aptly calls for 'turning waste into a resource', which implies waste prevention. 'Waste management' merges with 'from waste to resources' and leads to the era of ' $D$ ', shifts from 'end-of-life' to 'as-good-as-new' resources (de-alloy, de-composite, de-construct, de-polymerise) driven by economics of value presentation and $R \& D$ in material sciences.
Figures 2 and 3 summarise the nature of three economies (starting with the linear industrial economy) and detail opportunities and risks of two concepts, the circular economy and the performance economy. All three are 'industrial' economies, driven by research, innovation and competitiveness on a corporate and policy level.

A proposal for a different approach to 'map' the circular economy and its opportunities.

- The EC CE Package structures a circular economy as a result of the industrial economy (production, consumption, end-of-pipe waste). It covers manufactured goods (the tech-cycle) mainly by revising the 2008 Waste Directive, and food and water (the bio-cycle), the two cycles share the objectives of zero waste and resource loss prevention.

- This approach starts from the key objective of a 'valuepreserving stock management' to structure the circular economy; then uses backcasting to define the opportunities, risks and challenges: research topics, novel policies and (reversed) incentives. The authors' approach looks only at manufactured goods (the tech-cycle) as the era of ' $R$ ' offers limited opportunities in the bio-cycle. Yet tech-cycle and bio-cycle share many research challenges, such as undiluted collection of used goods (urea) and recycling atoms.

The circular economy map (previous page), adapted to the EC CE Package diagram, distinguishes four 'economies' of different nature, which ask for appropriate reactions.

- Production - the linear industrial economy based on value added and flow optimisation, the role of which is to bring innovative goods, services and systems to market, ruled by original equipment manufacturers (OEMs).

- Use - the era of ' $\mathrm{R}$ ': responsibility for reuse, repair, remanufacture, reprogram goods - the 


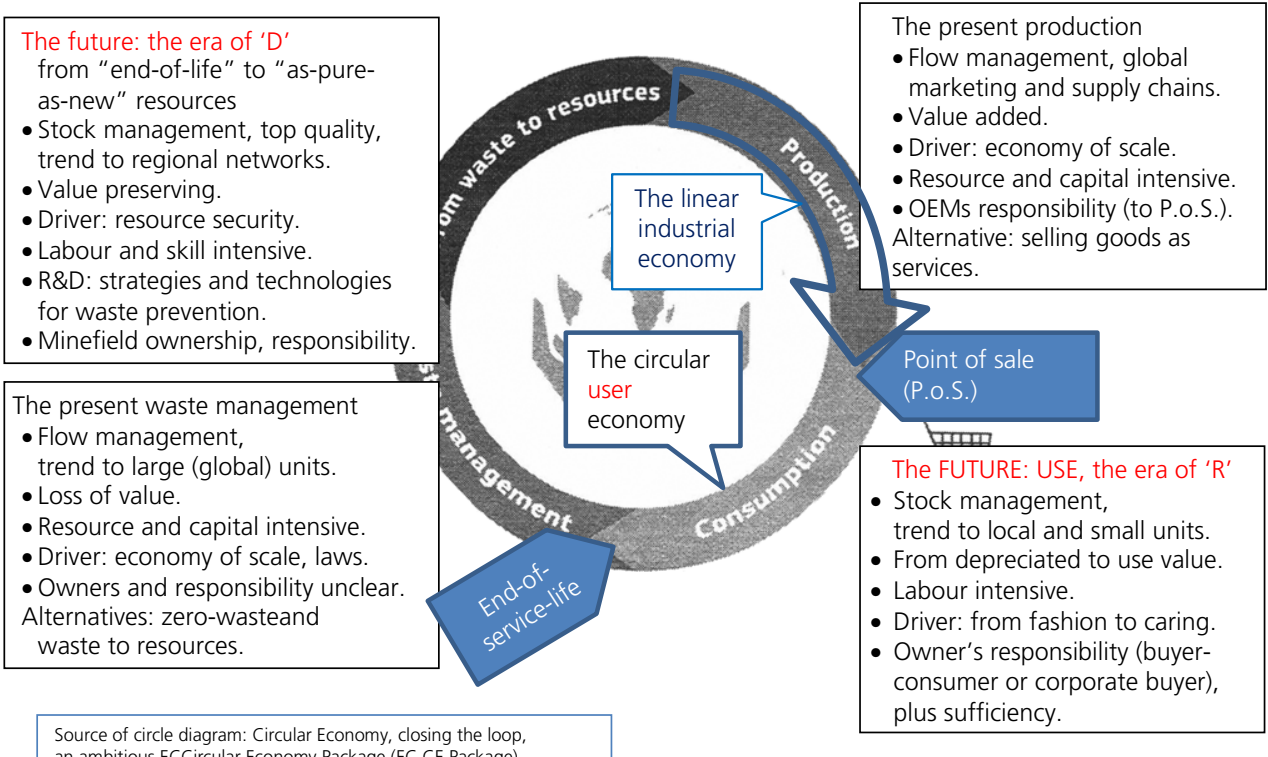

Figure 1. The circle of the EC CE package, my vision of the tasks of the future CE in square boxes

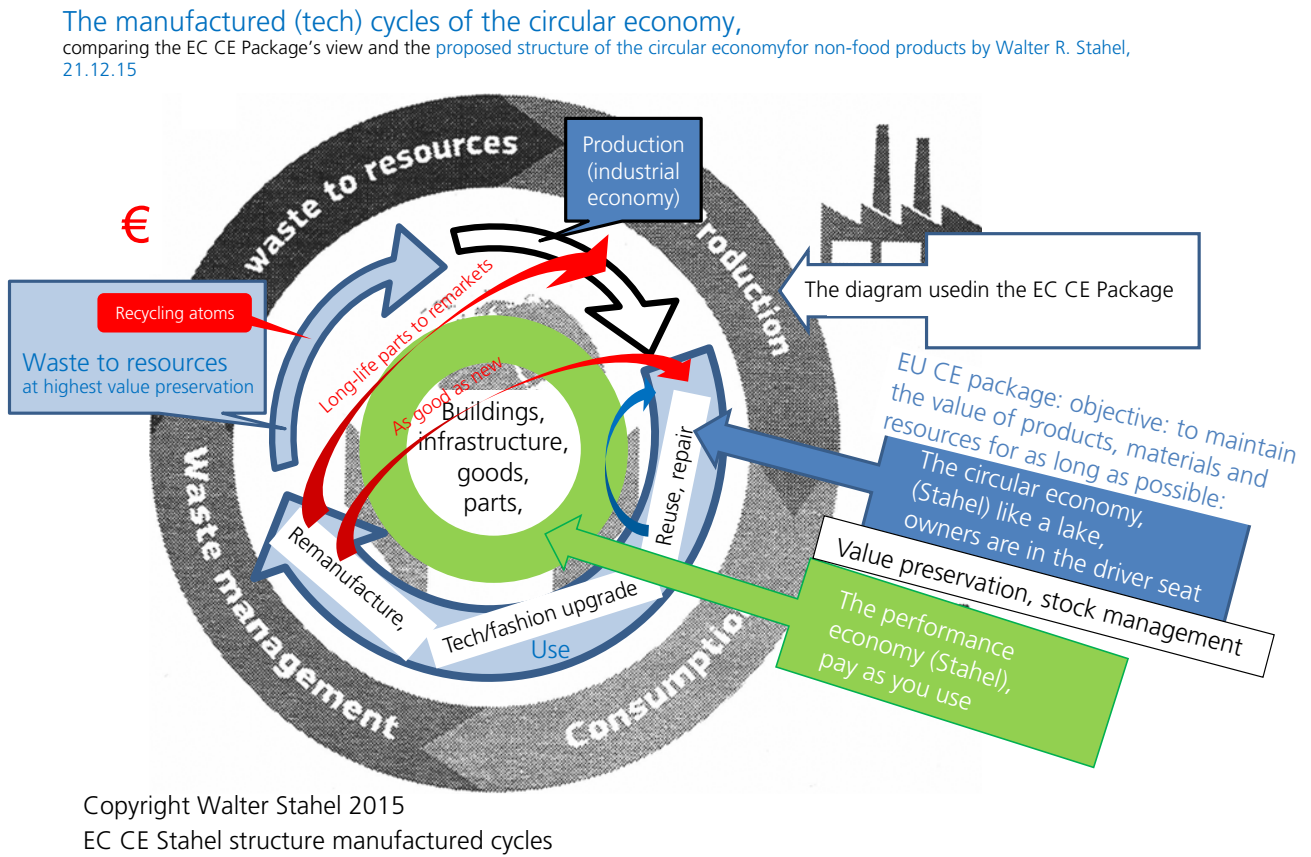

Figure 2. The outer ring is the EC CE diagram, the inner rings my vision of a future CE

Circular Economy Proper; like a lake, quality and quality of the stock define wealth; governed by owner-user responsibility of individuals and corporates, by caring.
- Transform - the era of 'D' skills to de-alloy, de-composite, de-laminate, de-polymerise, de-construct, de-vulcanise. The challenge to transform 'end-of-life' into 'as-good-as-new resources'. 


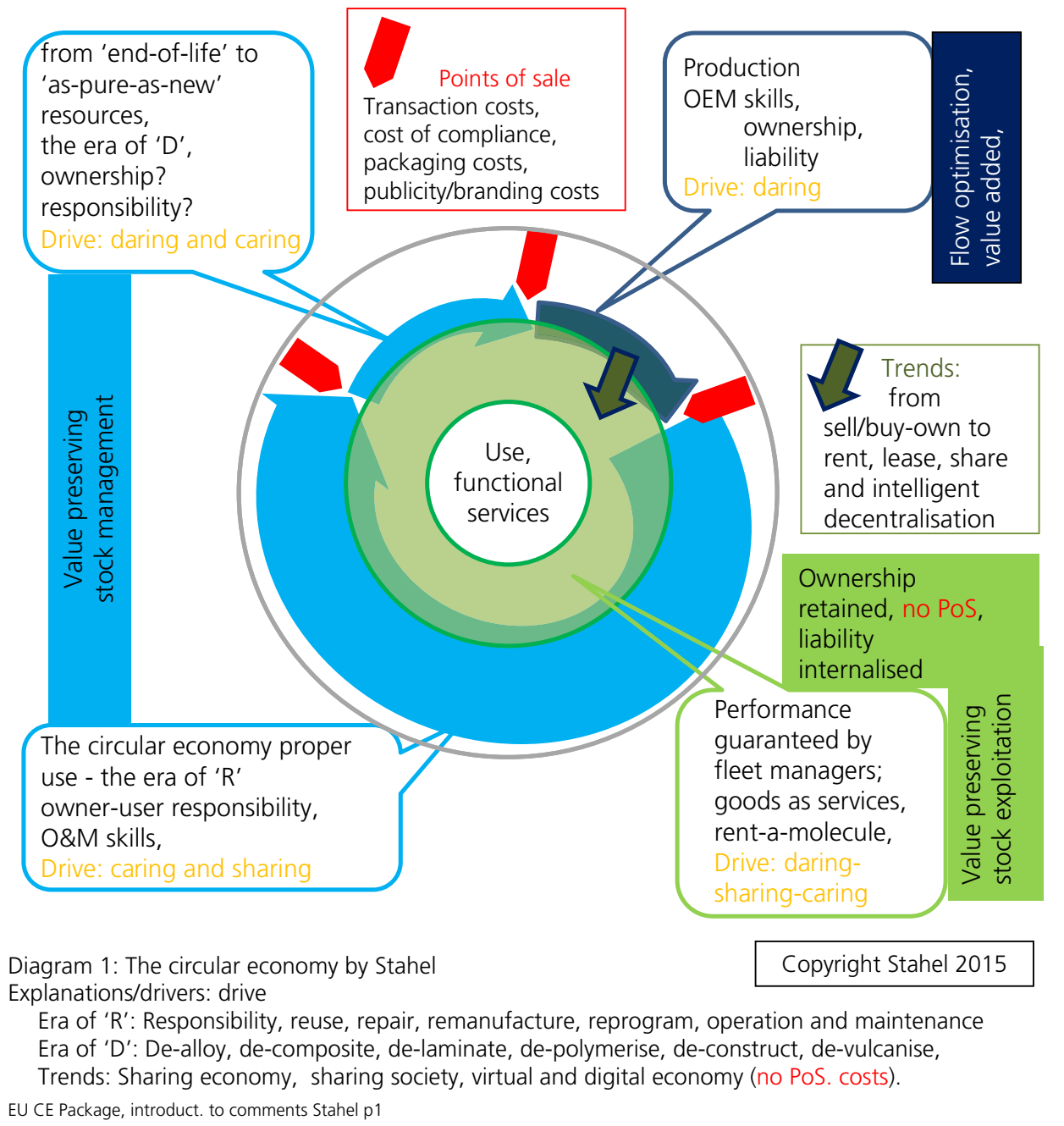

Figure 3. Stahel's vision of a sustainable CE

- The Performance or functional service Economy, sells goods and molecules as service through rent, lease and share business models; integrates production and the era of ' $\mathrm{R}$ ' and ' $\mathrm{D}$ '; and the costs of risk and waste to achieve higher competitiveness and profits.

The main suggestions for consideration are an increased performance approach in polices and legislation adding 'junction' issues, risk and opportunity management issues using incentives as levers to integrate trends and innovation into the forecasts of the EC CE Packages.

Change policy thinking from efficiency in managing waste flows to value-preservation performance in managing resource stocks (caring). Corporate performance is measured by turnover and profit; incentivising economic actors to switch from physical flow to service income will speed up such trends as rent-share-lease business models, as wells as such systems as chemical leasing/rent-a-molecule, which enhance pollution prevention and facilitate through Toxic Release Inventory; foster innovation by developing polices to valorise the loops within the era of ' $R$ ' and promote innovation in the era of ' $D$ '.

'Junction' issues in high-value end-of-life resource management clash with present legislation and efficient waste collection, the impact of eco-design methods on efficient take-back-for-reuse and explain the emergence of value, instead of cost, in waste. There are also issues in stock management activities (natural, cultural, health, human, acquired and manufactured capital), caring as motivation by users, regionalising the economy, labour skills, tax exemption on value-preserving activities and the legal definition of quality (performance). There are also 'junction' issues in selling performance: polices to incentivise producers to sell performance; integrate 'buying performance' 
into public procurement; shared responsibility of owners and users in rent-lease-share; national resource vulnerability through retained ownership by corporates.

Risk and opportunity management that reflect the change in value from waste (negative) to resources (positive) jeopardies today's role of state against economic managers; doubling the service life of goods reduces related production and waste volumes by half. Industrial ecology and symbiosis incorporate new systemic risks. Opportunities of multidisciplinary solutions are difficult to judge and handle by silo structures in academia and administrations.

Tailor incentives to reward responsible use by individuals and corporations to the specific Drive (motivation) model, for example; reward labour and skill intensive activities by not taxing work. Incentivise and reward economic actors for internalising external costs and value-preserving resource stock exploitation

\section{Conclusion}

A new EU research programme, Critical Raw Material Closed Loop Recovery, funded by the EU LIFE programme, is to invest in trials to demonstrate innovative new methods for the collection and reprocessing of waste electronic and electrical equipment (WEEE), hopefully leading to increased recovery of critical raw materials.

These materials are crucial to many electrical products, and the increasing pressure on their supply is a growing economic concern for businesses and governments. Prior research has shown that nearly $40 \%$ of electrical products go to landfill when they are disposed of (Wrap, 2014). Findings will be fed back to the European Commission in the form of policy recommendations and proposals for infrastructure development for the cost-effective recovery of the target materials. Four countries will participate - UK, Germany, Italy and Turkey, with each country representing varying maturity stages of recovery development, allowing cross-comparison so that a EU-wide framework can be developed.

Fostering research is great, but should policymakers not also fight abusive behaviour, such as deliberate waste? Fighting planned obsolescence, defined as consumer products suffering a defect shortly after their warranty period has ended, has become popular in Europe, even if it is difficult to prove.

But what about the madness of service-life abortion by OEMs, which results in direct resource loss and is easier to prove?

It appears that in a 2015 update of its iOS 7 operating software, Apple introduced a blocking mechanism to prevent 'unauthorised' people from using iPhones and iPads. Even if all data has been deleted and the default options reinstalled, the product can only be restarted using the original Apple ID and password.

Lost and Found offices - such as Fundsachenverkauf (2017), receiving all objects left behind in Swiss public transport and airports - have in the past checked that the objects had not been announced as stolen and then sold them at a reduced price for reuse, as is practice for all 'found and not reclaimed' objects of value in working order, such as children prams, umbrellas and musical instruments (Beobachter, 2016).

As Apple refuses to de-block these products, they now have to be recycled as electronic waste (WEEE, the subject of the new EU research programme). Not only is this a waste of scarce resources which could be prevented, it also increases the cost of a public service - the Swiss Lost and Found office quoted stores 800 used iPhones, iPads and iPods with a potential sales value of CHF 200'000, which it cannot sell. Apple's refusal also violates a key principle of the industrial economy: at the point of sale, ownership and liability are passed to the buyer.

Apple here retains a quasi-ownership of its products, which it had sold to a buyer at full price. By abandoning his or her property, the buyer passes the integral ownership rights to an unknown finder-keeper who in turn can sell it to whoever wants to buy it, as any second-hand or pre-owned object. This increases the overall welfare and reduces electronic waste and its cost.

Reuse before recycling has been an objective of the $2008 \mathrm{EU}$ Waste Directive, and has been reconfirmed in the 'Circular Economy Package (CEP, 2016) to help European businesses and consumers to make the transition to a stronger and more circular economy where resources are used in a more sustainable way' of the European Commission (EC, 2015), published on 2 December 2015.

Where are the policymakers to enforce the waste prevention objective of the environmental law in practice?

\section{REFERENCES}

Beobachter (2016) http://www.beobachter.ch/archiv/inhaltsverzeichnisse/ editionsarchiv/2016/12/1/ (accessed 30/03/2017).

CEP (Circular Economy Package) (2016) http://www.europarl.europa. eu/EPRS/EPRS-Briefing-573936-Circular-economy-packageFINAL.pdf (accessed 30/03/2017).

EC (European Commission) (2011) http://ec.europa.eu/environment/ resource_efficiency/about/roadmap/index_en.htm (accessed 30/03/2017)

EC (2015) http://ec.europa.eu/environment/resource_efficiency/about/ roadmap/index_en.htm (accessed 30/03/2017).

Fundsachenverkauf (2017) http://fundsachenverkauf.ch/ (accessed 30/03/2017)

Wrap (2014) http://www.wrap.org.uk/content/switched-value (accessed 30/03/2017) 